\title{
METEOROLOGICAL CONDITIONS OVER PUERTO RICO DURING HURRICANE BETSY, 1956
}

\author{
JOSÉ A. COLÓN \\ U.S. Weather Bureau, San Juan, P.R. ${ }^{1}$ \\ [Manuscript received January 28, 1958; revised November 28, 1958]
}

\section{ABSTRACT}

\begin{abstract}
The observations of wind, pressure, rainfall, and radar bands recorded over Puerto Rico during the passage of Hurricane Betsy are presented and discussed. The track of the hurricane across the Atlantic and eastern Caribbean Sea, which shows an apparent sinusoidal oscillation around the mean path, is also included. The radar observations are used to obtain the detailed path of the hurricane across Puerto Rico and to study the changes in the structure of the precipitation bands that resulted from the passage over the mountainous section. Photographs are presented to illustrate the variations in the radar structure. Some inferences are made in regard to the changes in the intensity of the wind and pressure fields. It is shown that some weakening of the wind field and filling of the central pressure occurred with motion over the land area, and that rapid deepening followed as soon as the hurricane moved over water on the north side of the island. The rainfall observations are compared with those recorded in the great "San Felipe" hurricane of September 13, 1928.
\end{abstract}

\section{INTRODUCTION}

On August 12, 1956, hurricane Betsy, the second tropical storm of the season, moved across the island of Puerto Rico. It was the first hurricane to pass directly over the island since September 24, 1932-a period of 24 years. Hurricane Betsy was a fast-moving storm of relatively small size and its effects, fortunately, did not compare with the larger and more severe hurricanes of the past, like the "San Felipe" hurricane of September 13, 1928, and the "San Ciriaco" of August 8,1899."

From a meteorological point of view the occurrence of hurricane Betsy was significant in that it provided an opportunity to obtain observational data of a nature and scope never before possible in the eastern Caribbean area. The installation of storm-detection radar at San Juan was completed a few days before the arrival of hurricane Betsy and provided a first hand view of the changes taking place in the radar configuration as the hurricane moved across the mountain range of Puerto Rico. Observations by airborme radar gave valuable information on the storm during the period previous to its arrival at Puerto Rico. Considerable radar and aerological data were also obtained after the hurricane passed Puerto Rico and moved along the net of stations in the Bahamas Islands. This report is concerned only with the meteorological aspects of hurricane Betsy over Puerto Rico and the area to the east. Emphasis is placed on the changes in the structure of the hurricane caused by the motion over the mountains of Puerto Rico.

\footnotetext{
1 Present affiliation: National Hurricane Research Project, Miami, Fla. 2 According to the traditional method of naming hurricanes after the saint's day on which they occurred, hurlicane Betsy was baptized in Puerto Rico as "Santa Clara."
}

\section{SYNOPTIC HISTORY}

Hurricane Betsy was detected on August 9, 1956, near latitude $14^{\circ} \mathrm{N}$, longitude $49^{\circ} \mathrm{W}$. with the aid of ship reports [1]. Reconnaissance aircraft penetrated the storm for the first time on the afternoon of August 10 and reported a small but well developed system of hurricane intensity. The maximum winds were 100 knots in the southwestern quadrant, 90 knots in the northern, and 75 knots in the eastern quadrants. The minimum pressure was $979 \mathrm{mb}$. and the eye diameter $20 \mathrm{n}$. mi. The radius of the circulation was quite small with 45 -knot winds extending only $60 \mathrm{n}$. mi. to the north and $50 \mathrm{n}$. mi. to the south of the vortex.

The hurricane moved westward to west-northwestward and passed over the island of Guadeloupe, F.W.I., around 1200 gMT of August 11 (fig. 1.). Considerable damage was reported in the islands of Guadeloupe, Marie Galante, Dominica, and Les Saintes. The hurricane continued to move generally west-northwestward over the eastern Caribbean Sea and arrived on the southeastern coast of Puerto Rico around 1200 GMT (0800 LST), August 12.

\section{OSCILLATORY MOTION IN THE TRACK}

During its motion over the Atlantic and eastern Caribbean Sea hurricane Betsy was almost continuously tracked by reconnaissance aircraft. Center fixes based on airborne radar observations were available at 30-minute intervals during a considerable part of the period from the morning of August 11 onward (fig. 1). If all the fixes are taken at full value, a sinusoidal variation around the mean path is quite evident. Such oscillations in hurricane tracks have been the subject of discussion among 


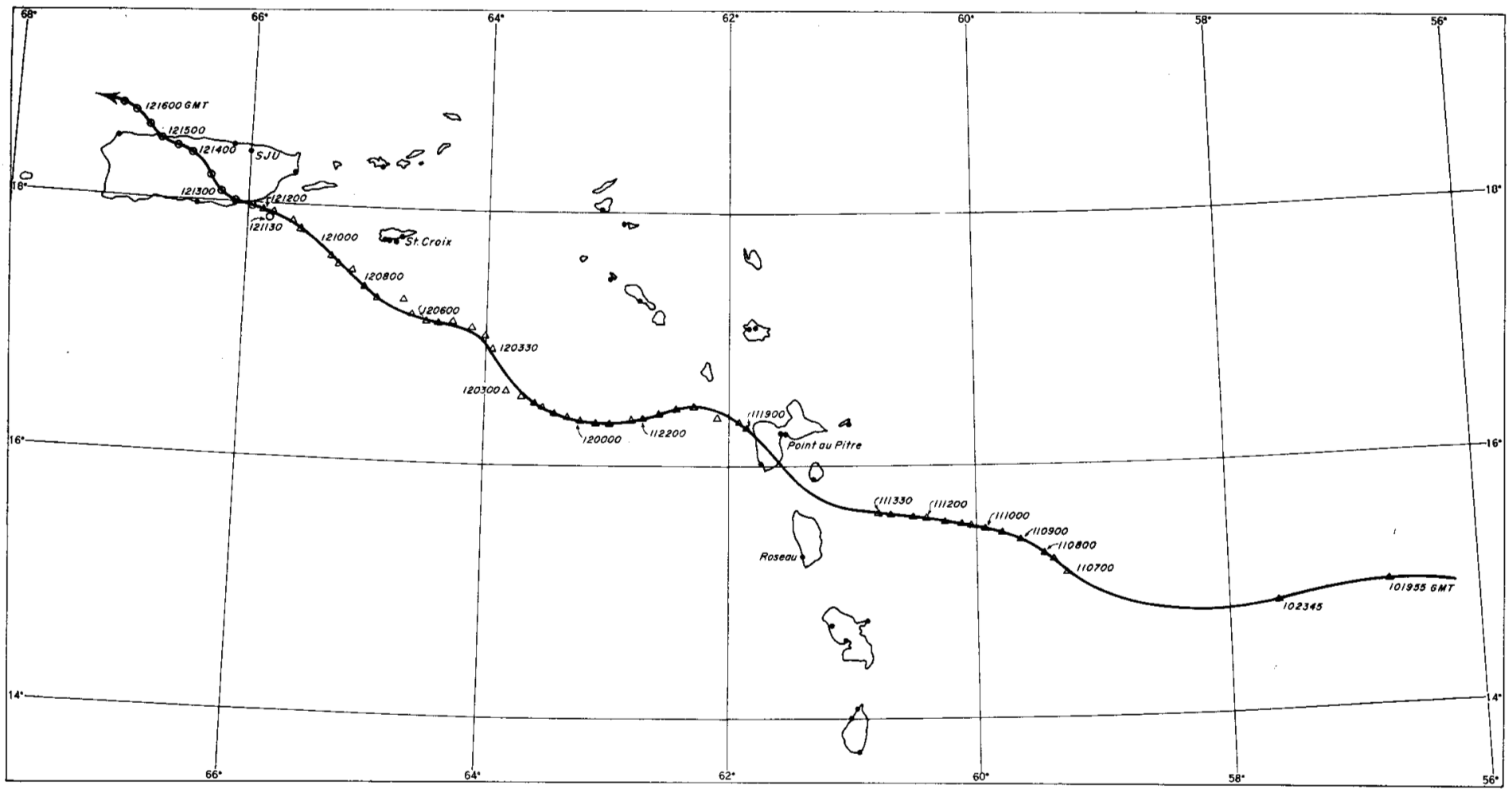

Figure 1.-Track of hurricane Betsy, August 10-12, 1956. Aircraft positions indicated by triangles, positions from San Juan radar by circles. Positions for which no time is directly indicated are in 30-minute intervals.

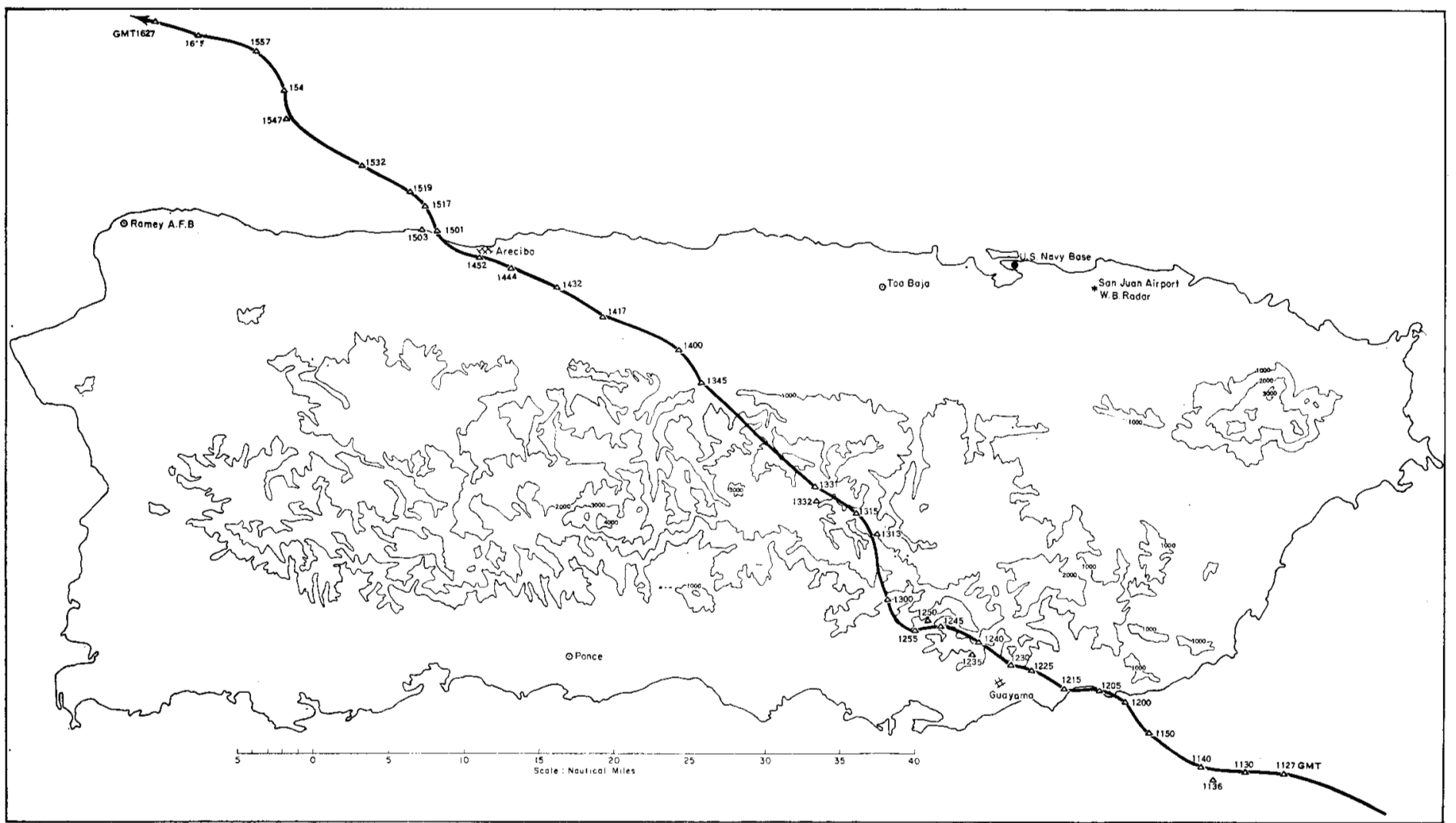

Figure 2.-Track of hurricane Betsy across Puerto Rico as determined from San Juan radar. Contours in 1000-ft. intervals. 
tropical meteorologists during the last 10 years $[3,4,7]$. Ordinarily people are inclined to disbelieve them because the amplitude of the variations often is of about the same magnitude as the errors in determining the center fixes.

The two most important sources of error in determining center positions with airborne radar are the navigational errors in the position of the aircraft and the errors in determining the exact center of the radar bands. In the case of hurricane Betsy the reconnaissance aircraft were flying at all times over or near the neighboring islands and therefore navigational errors were probably at a minimum. The set of positions between 0700 and 1330 GMT August 11 were obtained by an airplane operating in the vicinity of the islands of Dominica and Martinique at an altitude close to 10,000 feet. According to the reports from the aerologist aboard, the storm consistently presented excellent eye targets, with a precipitation eye mostly circular, 9 to $15 \mathrm{n}$. mi. in diameter. The navigation was reported as accurate within $3 \mathrm{n}$. mi. Between 1900 GMT August 11 and 0300 Gмт August 12 a different aircraft tracked the center mostly from the right or northward side of the hurricane around the islands of Antigua, St. Kitts, and St. Croix. After 0330 GMT a third aircraft operated from the vicinity of Puerto Rico and the Virgin Islands. Judging from the reports of the reconnaissance aircraft and from the appearance of the hurricane when it came within range of the San Juan radar (fig. 3), the radar eye was well-defined and generally closed so that errors in placing the center should also have been small. Throughout the period, errors in the center fixes were reported as from 3 to $5 \mathrm{n}$. mi. which is well below the estimated amplitude of the oscillation. There was only one serious discrepancy in the continuity of the center fixes and it occurred between 0300 and 0330 GMT, August 12, at the time of a change in the observing aircraft, when the first position obtained by the new observer did not make good continuity with the last position of the departing one. However, all factors considered, it appears that the accuracy of the reports shown in figure 1 is as good as can ever be expected.

The wavelength of the oscillation of the track (fig. 1) was of the order of $160 \mathrm{n}$. mi. in the eastern section of the track and decreased to around $100 \mathrm{n}$. mi. farther west. This indicates a period of about 7 to 12 hours. The amplitude was 10 to $15 \mathrm{n}$. mi., but decreased and was practically insignificant in the vicinity of Puerto Rico. These values for the period and amplitude are considerably smaller than those reported previously in the literature $[3,4,7]$.

\section{PATH OF THE STORM CENTER ACROSS THE ISLAND}

Figure 2 shows the path of the center across the island on a base map that contains height contours at $1,000-\mathrm{ft}$. intervals. The mountain system consists essentially of an east-west oriented range with highest peaks a little over 4,000 feet. The storm moved inland in a section where the coastal lowland is very narrow and the height of the terrain rises rapidly. The highest peaks in the section along the track are close to 3,000 feet.

All the center positions in figure 2 were evaluated from the radar film obtained at San Juan, and indicate the approximate center of the radar eye. Up to 1300 GMT the eye was well defined (see figs. 3 to 7 ) and the accuracy of the fixes good. Between 1300 and $1400 \mathrm{GMT}$, while the center was moving over the mountains, the eye structure deteriorated and it was then more difficult to determine the exact center of the hurricane. Another cause of difficulty in the tracking was the inability to operate the radar continuously. After 1300 смт, because of severe interference with local communications, the radar equipment was operated only for 3-minute intervals every 15 minutes. With such a gap in the observations it was more difficult to maintain continuity of the eye opening. At 1400 GMт and afterwards the center was located in the northern lowlands and reformed rapidly. The fixes after that time are more reliable. In the evaluation of the track proper consideration was given to the independent fixes obtained by the radar technician at the time of the hurricane.

The path in figure 2 has been drawn connecting most of the fixes, but no significance is claimed for all the minor variations. Some changes in the direction of motion, however, appear to have been significant. For example, between 1130 and 1300 GMT the average direction was around $290-295^{\circ}$; between 1300 and 1400 GMT the motion was toward $315-320^{\circ}$; and after 1400 GMr it was around $300-305^{\circ}$. It is interesting to see that these changes in direction fit rather well into the pattern of the oscillation evident previous to the arrival of the center over the island.

\section{CHANGES IN THE RADAR STRUCTURE}

Figures 3 to 14 present a series of photographs of the San Juan radarscope showing the structure of the hurricane at different positions over the island. The approximate position of the storm at the time of each photograph can be determined from figure 2 . In this series of pictures the echoes from the southeastern side, between directions $120^{\circ}$ and $150^{\circ}$ bearing from the center of the scope, are partially obscured due to physical interference from the San Juan Airport Control Tower, located on the roof a short distance from the radar antenna. Because of this interference the hurricane was not completely visible on the radar screen until just a few minutes before the time of figure 3 .

Figure 3, taken at 1207 GMT when the hurricane was centered over the southern coast, shows a circular and welldefined inner band. The outer diameter is around $30 \mathrm{n}$. mi. and the inner diameter $13 \mathrm{n}$. mi. so that the inner band is $8-9 \mathrm{n}$. mi. wide. There is a sector of weak echoes, almost an opening, on the west side. The outline of the bands near the center of the scope is obscured by the 


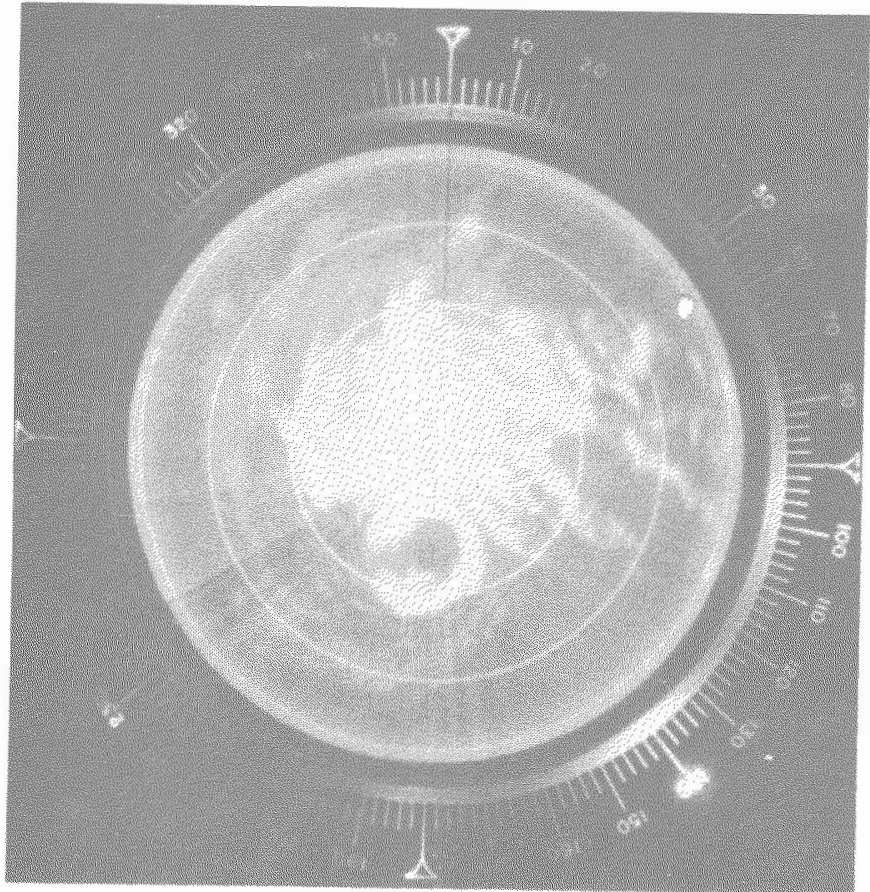

Figure 3.-Photograph of radarscope of San Juan radar at 1207 GMT, August 12, 1956. Range markers 20 nautical miles apart.

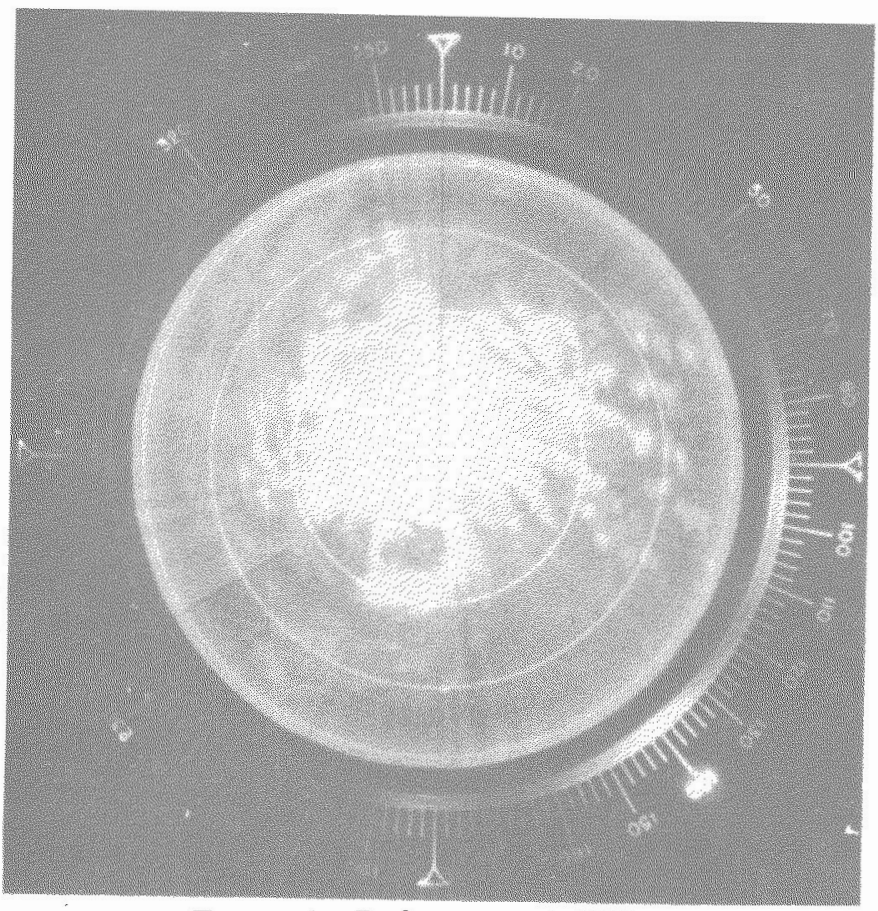

Figure 4.-Radarscope at 1230 GMT:

ground return, but several bands can be identified on the northeastern side of the hurricane spiraling toward the eye. On the far or southern side of the storm one band is barely discernible following closely the $60 \mathrm{n}$. mi. range marker. At the time of the photograph the storm was centered on the coast with the northern half over land and the southern half over water, but this difference in the underlying surface does not seem to have made much difference in the appearance of the radar echoes.

The outline and configuration of the radar band re-

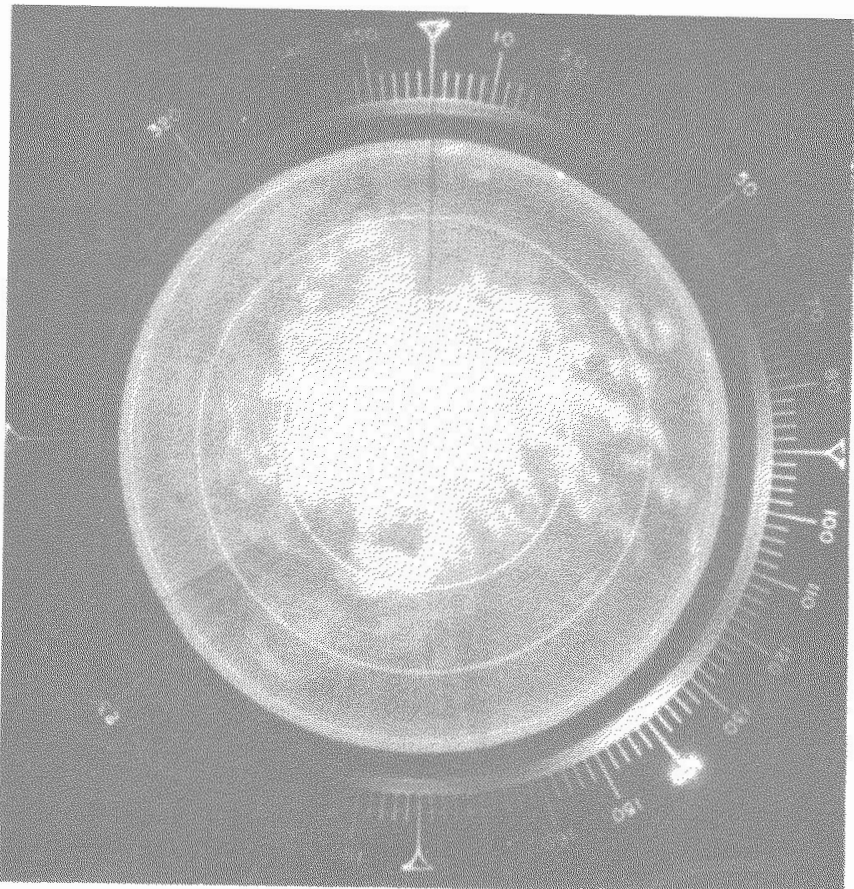

Figure 5.-Radarscope at 1234 gмт.

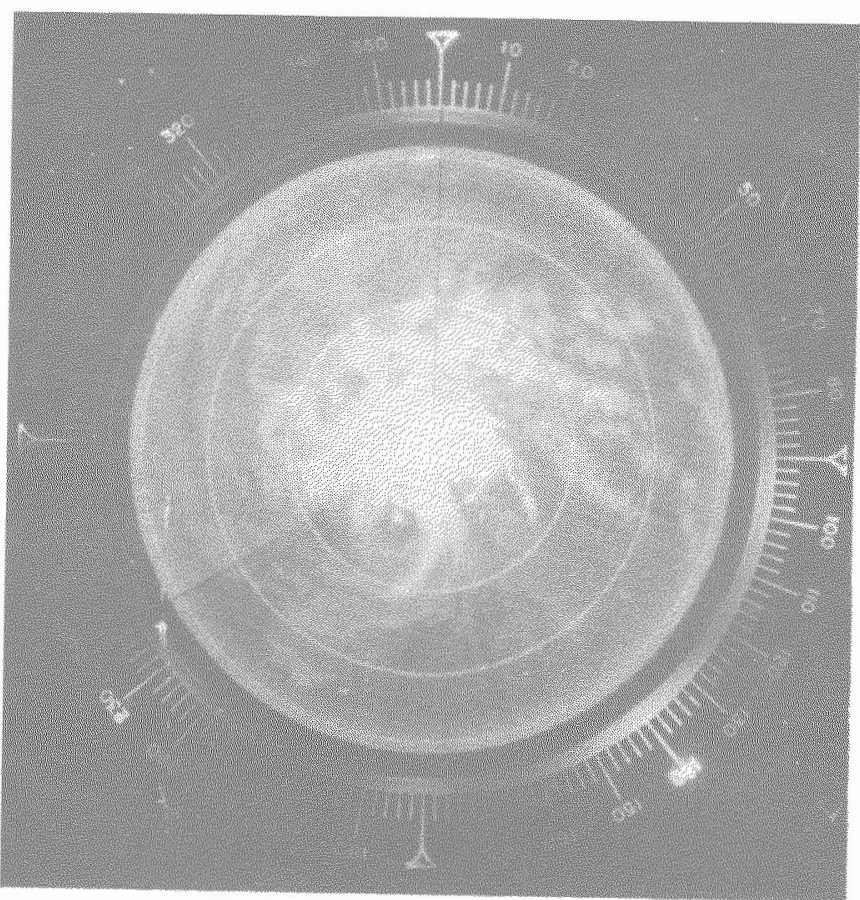

FIGURE 6.-Radarscope at 1247 gMT.

mained practically unchanged during the following 15 to 20 minutes, as the storm moved gradually inland. By 1230 GMT (fig. 4), with the eye center located about 4 n. mi. north of the coast, the inner boundary of the eye had taken a sort of rectangular shape. The edges of the main band were also becoming ill-defined. A few minutes later, at 1234 GMr (fig. 5), the eye showed an almost perfect rectangular form. This lasted a few minutes and then began to deteriorate. At 1247 GMT (fig. 6) the central band showed significant changes; the inner diameter was smaller, the echoes from the southern side were 


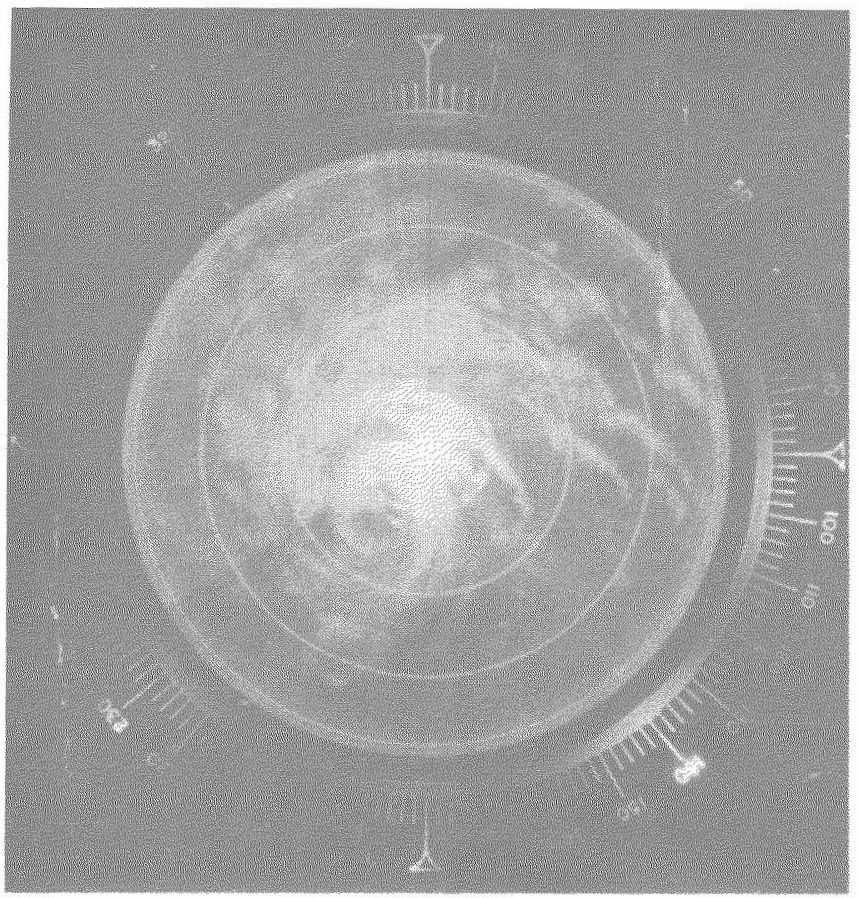

Figure 7.-Radarscope at 1302 gмт.

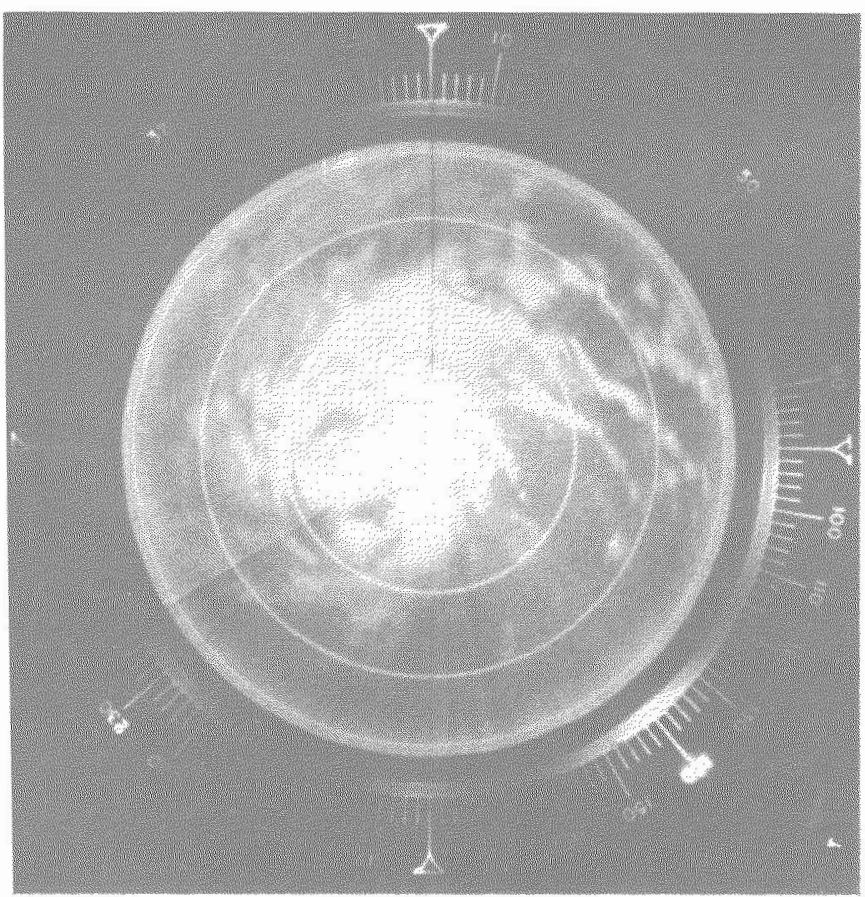

FiguRE 8.-Radarscope at 1312 gMT.

weaker, and the shape of the band look more like a spiral in contrast to the ring-like structure shown previously. At this time the center had traveled over land for about $12 \mathrm{n}$. mi. and was located in the southern slopes which have an altitude of around 1,000 feet.

At about this time the observer in charge of the radar raised the antenna and was able to notice a northwestward slope of the central band. This was explained as due to the effect of the mountains that detained the lower part of the system while the upper part continued its forward displacement [5].

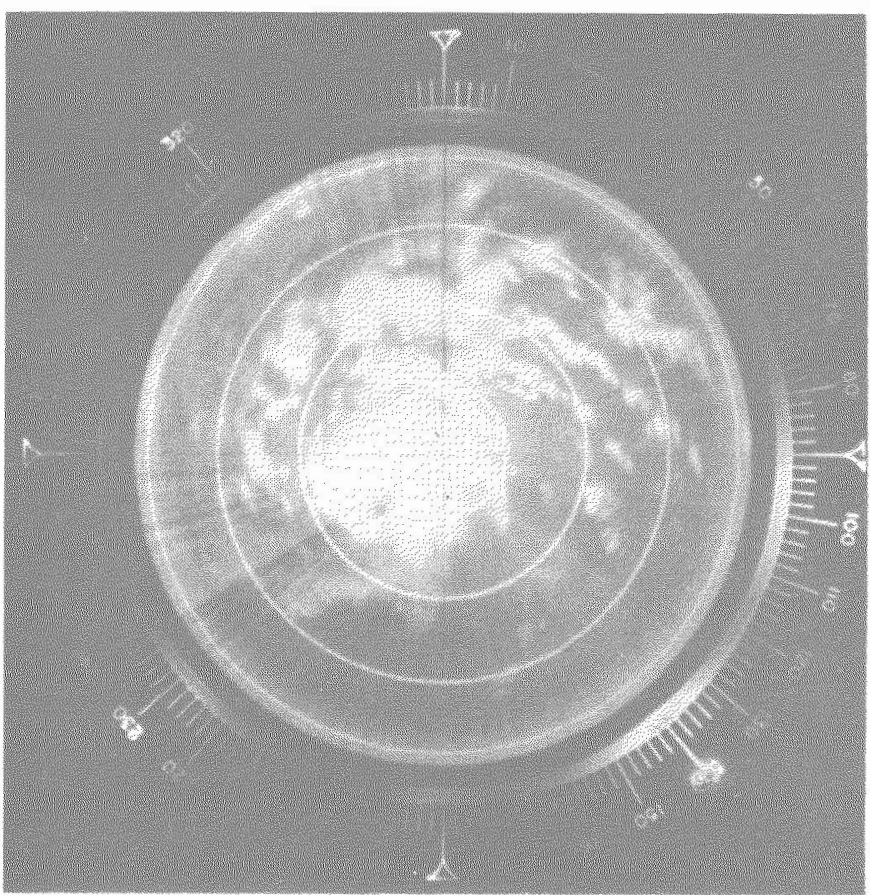

Figure 9.-Radarscope at 1331 gMt.

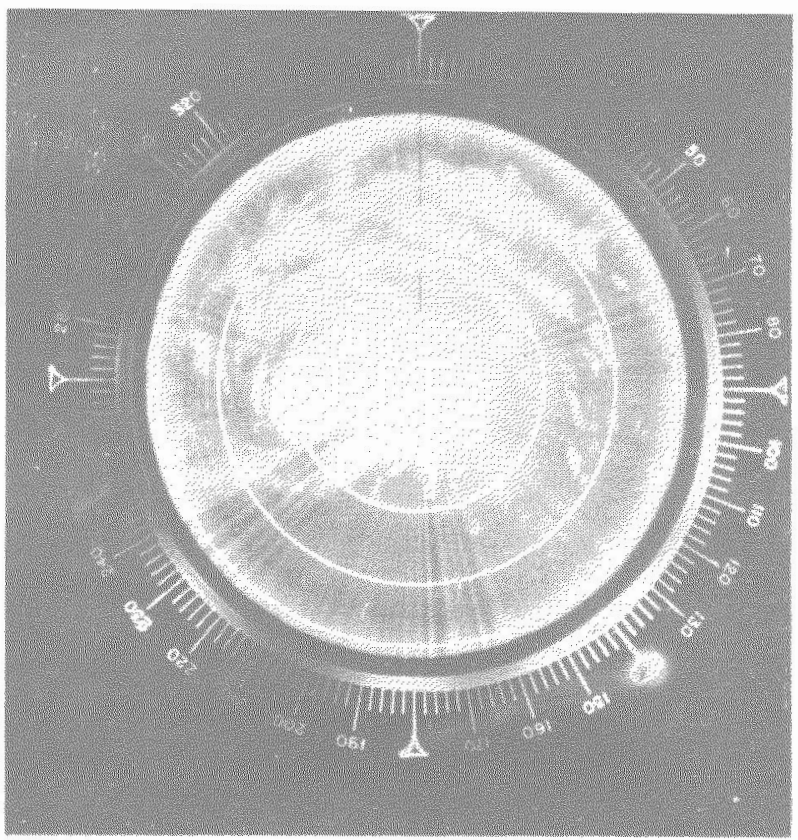

Frgure 10.-Radarscope at 1402 GMT.

At 1302 GMT (fig. 7) the center was still south of the main mountain ridge. The inner band showed a spiral structure open to the south-southwest. Figures 8 and $\mathbf{9}$, taken at 1312 and 1331 GMT, respectively, show the storm when it was located on top of the mountains at an altitude of over 2,000 feet. The eye opening was then very small, indistinct, and irregularly shaped. The configuration of the outer bands on the northern semicircle had not changed appreciably; most of the changes occurred in the inner core of the system.

In the determination of the radar track the center of 


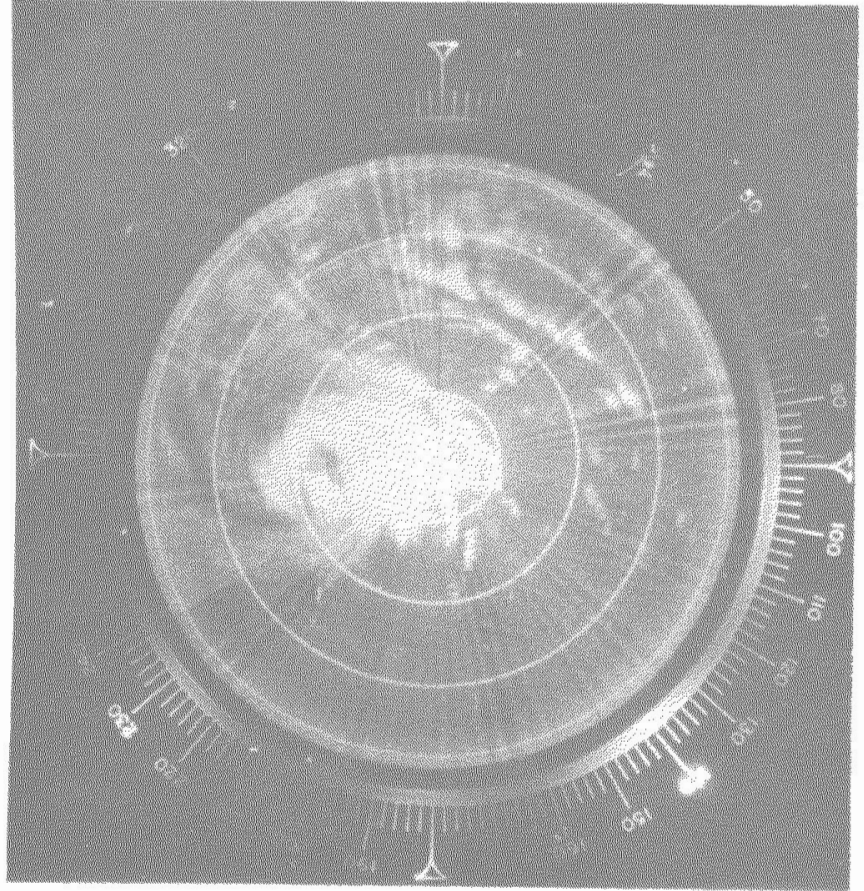

Figure 11.-Radarscope at 1417 GMT.

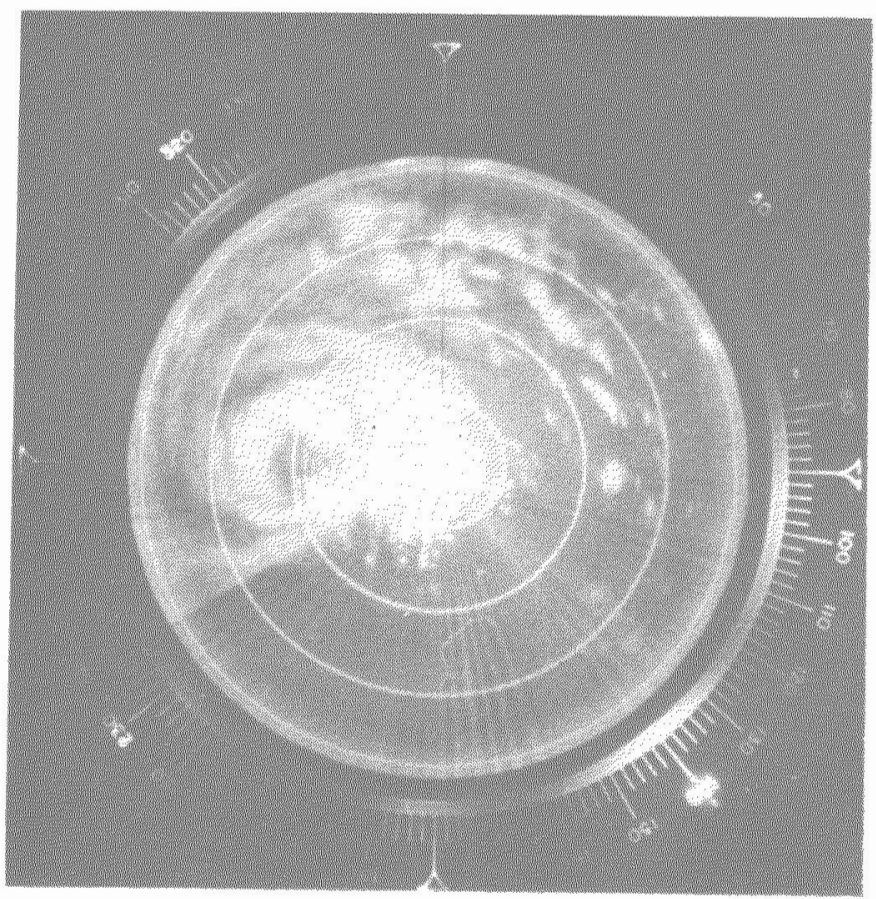

FIGURE 12.-Radarscope at 1447 gMT.

the opening was taken in each case as the center of the eye, but it is possible that that point did not exactly coincide with the center of the eye as identified in previous pictures.

The next photograph (fig. 10), which was taken at 1402 GMT when the hurricane had just moved down the mountains, shows a very small eye opening. After 1400 GMT the eye began to widen and regain its original structure as the hurricane system moved away from the mountains. At 1417 GMT (fig. 11) the eye appeared already quite wide.

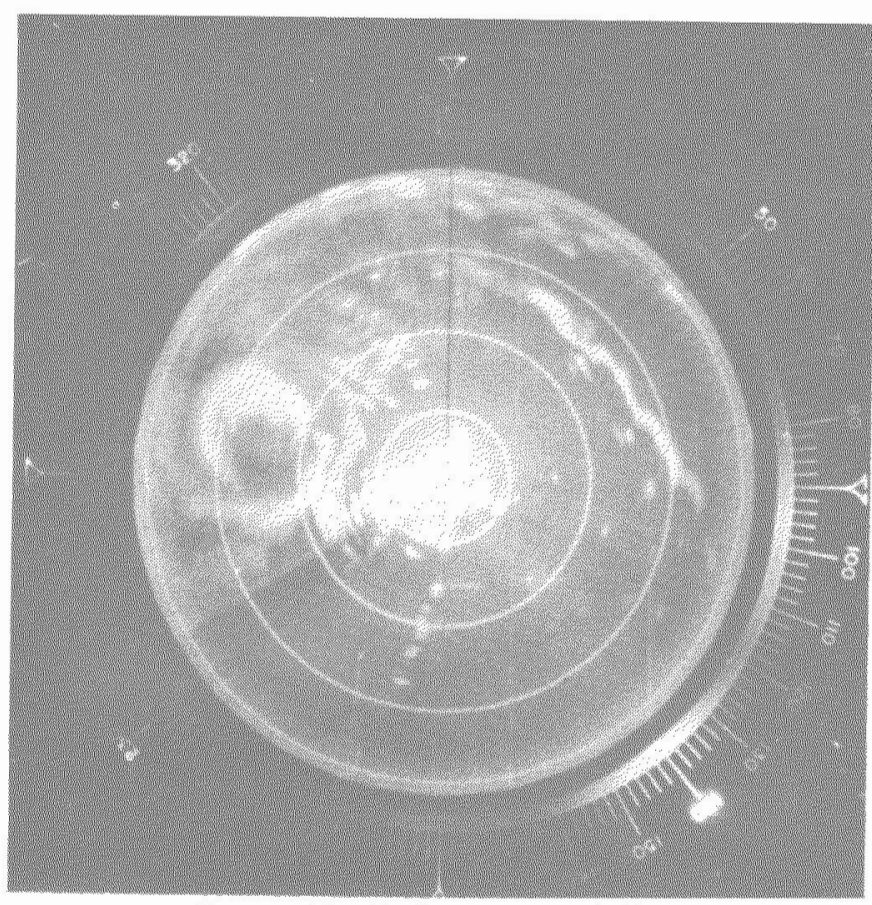

Figure 13.-Radarscope at 1532 git.

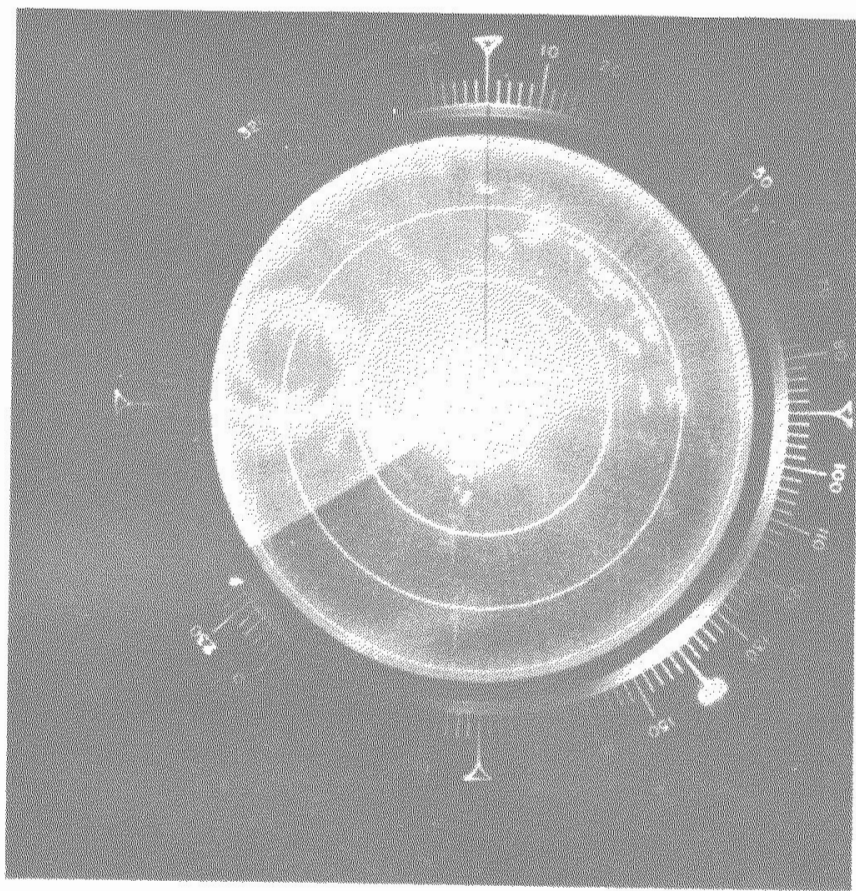

Figcre 14.-Radarscope at 1608 gmt.

Some echoes from the terrain are visible in the southern section of the eye. Figure 12, taken at 1445 GMT shows the storm centered close to the northern coastline, with an eye diameter of approximately $15 \mathrm{n}$. mi. The inner band appears practically complete. In figure 13 , at $1532 \mathrm{GMT}$, the hurricane center was located over water about $4 \mathrm{n}$. mi. north of the coast. The inner band shows a spiraling structure with an eye diameter of $18-20 \mathrm{n}$. mi. The last photograph, figure 14, shows the hurricane at 1608 GMT when it was located about $12 \mathrm{n}$. mi. north of the coast. 
The central band was then almost completely over water. Figure 14 shows a band structure quite different from the compact ring evident in figure 3.

There are a few significant points related to the changes in the radar structure. First, the progress of the hurricane system from a water to a land surface, and similarly from a land to a water surface, by itself did not seem to have much of an effect on the structure or appearance of the precipitation bands. Practically all the changes resulted from the motion over the mountainous section. The rapidity with which the inner band reformed as soon as it moved away from the mountains was striking.

An interesting point concerning the speed of motion of the center across the island was noticed and it may be connected to the changes in the radar structure. The average speed of the hurricane center across the island was 18-19 knots (a distance of $56 \mathrm{n}$. mi. from the point of entry to the point of departure, disregarding the minor variations in the path, in a period of 3 hours). The average speed in the 12- and 24-hour periods previous to the arrival of the center on the south coast, and also after the departure from the north coast, was in both cases only 15-16 knots. There was, apparently, a faster motion while the hurricane was moving over land. The fastest motion seems to have occurred between 1300 and 1400 GMT, but that was precisely the period during which the eye was more distorted and the accuracy in the center positions was less. Since the geometric center of the central opening, which was changing shape and diameter rapidly, was taken in each case as the eye center it is easy to see how discontinuities conld occur. In fact, a study of the radar film suggests that the eye formation that developed when the hurricane moved into the northern coastal area did not follow in exact continuity from the previously existent eye that had deteriorated over the mountains. This could account for the apparent acceleration. Unfortunately, due to the breaks in the radar picture, the phenomenon could not be verified unquestionably.

\section{WIND OBSERVATIONS}

Detailed wind observations were recorded at three stations on the island: San Juan Airport (Weather Bureau station); U.S. Naval Base, San Juan, located about $6 \mathrm{n}$. mi. west of the Airport; and Ramey Air Force Base, located on the northwestern corner of the island. At the Naval Base, in addition to the hourly, airways observations, a gust recorder giving a continuous graph of the wind speed and direction was available.

The winds in the San Juan area (fig. 15) were from the northeast with speeds of around 15 knots during the evening of August 11. No significant change in direction or speed was noticed until around 0530 to 0600 GMT August 12 , when a decrease to a near calm occurred. At that time the hurricane center was approximately $120 \mathrm{n}$. mi. away. The wind recorder at the Naval Base showed that the period of calm lasted for about 45 minutes. The speeds during the interval were never more than 5 lnots.
A rather strong shower, with a measurement of 0.30 inch of rainfall, was observed at the San Juan Airport at that time, and was the first heavy precipitation there associated with the hurricane. After 0600 GMT there was a slight increase in the speed and gustiness of the wind. The precipitation became light, but fairly continuous for the next 4 hours.

Another significant change in the character of the winds, and also of the pressure and rainfall, was noticed around 1000 GMT, when the center was about $50 \mathrm{n}$. mi. away. There was a sharp increase in the wind speed and in the intensity of the precipitation. At the same time the pressure curve showed a more rapid downward trend. That marked the beginning of the intense inner core of the hurricane. Thereafter the wind speed increased rapidly and steadily to its maximum which was recorded from 1200 to 1245 GMT. The precipitation started increasing a little earlier than the wind speed and continued heavy until shortly after the time of the peak gusts. The visibility curre, which to a large extent is a reflection of the intensity of the rainfall, made a sharp drop to around 1-2 statute miles about 0930 GMT and continued low until $1330 \mathrm{GMT}$. The maximum wind speed of around 65 knots with gusts to 80 was recorded at 1235 GMT. Afterwards the winds decreased rapidly; at 1300 GMT the reading was 38 knots with gusts to 52 . By 1400 GMT the wind had reduced to 26 knots with gusts to 43 , the precipitation had practically ceased, and the visibility had increased to near its normal magnitude. At that time, however, the storm center was located only $28 \mathrm{n}$. mi. away.

The maximum winds in the San Juan area were from the northeast; the southeasterly flow on the right rear quadrant was extremely light. The minimum pressure, $1003 \mathrm{mb}$., was recorded at around $1300 \mathrm{GMT}$, a little later than the maximum winds, but before the radar center had arrived at the point of minimum distance from the station. The radar center was closest to San Juan, at a distance of about $22 \mathrm{n}$. mi., near $1315 \mathrm{GMT}$; that is, about 40 minutes after the time of the peak gusts and 15 minutes after the minimum pressure. There was evidently a great. distortion in the hurricane circulation. The non-coincidence of the pressure eye with the circulation eye or the radar eye has been reported previously [6] as a more or less normal occurrence. In the present situation the motion of the hurricane over the mountainous area must have been the main factor in causing the observed irregular distribution in the meteorological parameters around the center.

The observations at the Naval Base, San Juan, agreed very well with those made at the Airport. The maximum winds, 46 knots with gusts to 67 , and the minimum pressure, $1001 \mathrm{mb}$., were both recorded at the same time as at the Airport. The lower speeds at the Naval Base were probably due to the differences in exposure; the Base is located on the western side of the city and has greater obstructions to an easterly flow than the Airport Station. 


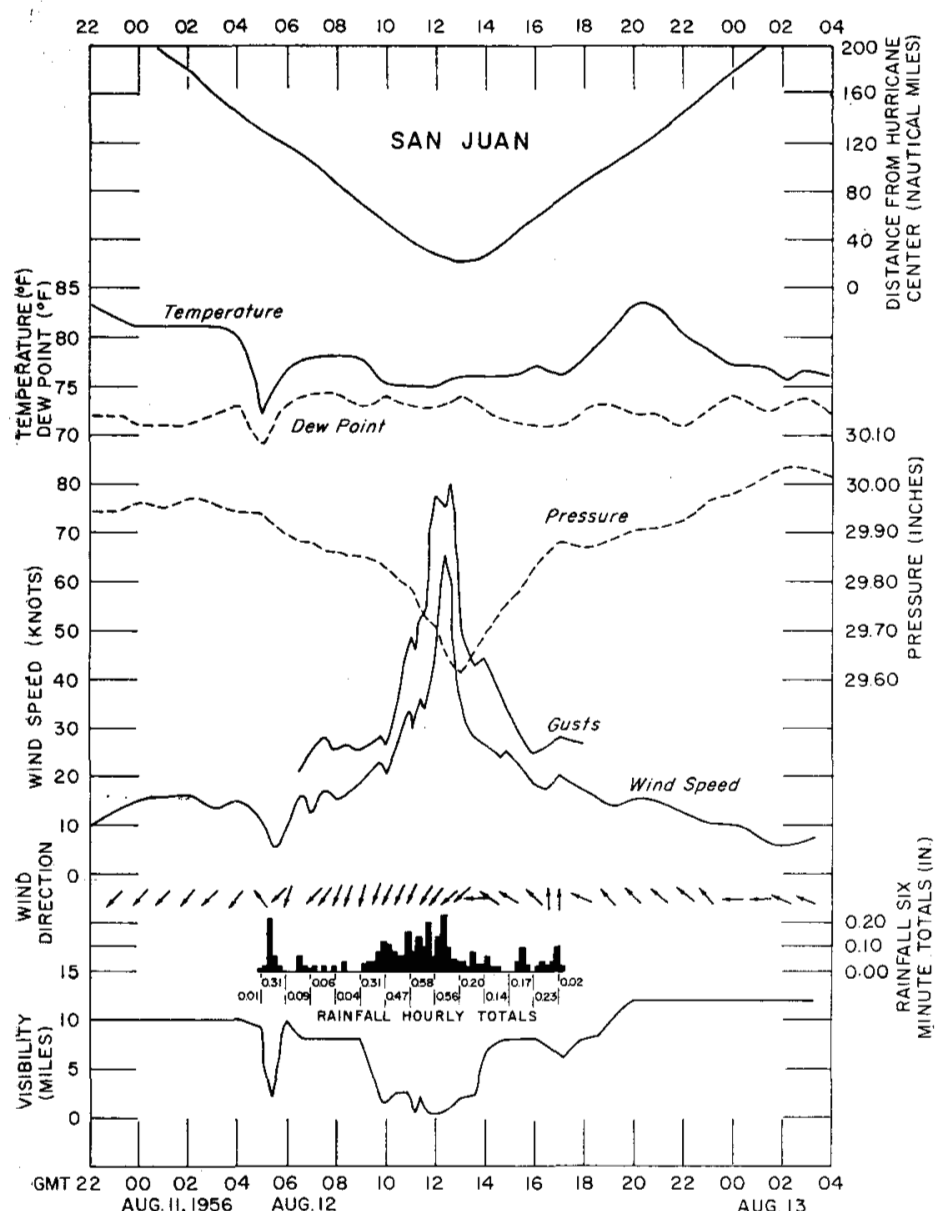

Figure 15.-Meteorological observations at the Airport Station, San Juan, P.R., during the passage of hurricane Betsy, August 12, 1956. Time scale in GMT.

Figures 3 to 6 , which show the radar pictures during the period of strongest winds and precipitation in the San Juan area, indicate that the activity there was associated with a radar band next to the central one.

The effect of the mountains in Puerto Rico on the isotach field around the center is revealed by the difference in the character of the wind speed variations at San Juan and at St. Croix, V.I. (fig. 16). Both stations were located on the same side of the hurricane and came within approximately the same distance of the center. The st:tion at St. Croix is located near the southern coast; the island is small and relatively flat so that distortions of the hurricane circulation due to the terrain should have been minor. The pressure and rainfall observations at the two stations showed very close agreement. St. Croix recorded a minimum sea level pressure of $1002 \mathrm{mb}$. and a total rainfall of 3.20 inches, as compared to $1003 \mathrm{mb}$. and 3.21 inches at San Juan. Both stations recorded around 2.00 inches of rain in the 6 -hour period of peak activity. The minimum pressure at St. Croix was recorded at the time of minimum distance from the center; the maximum winds were recorded a little later. There was, therefore, a better coincidence of the pressure and radar centers at the time the hurricane passed abeam St. Croix.

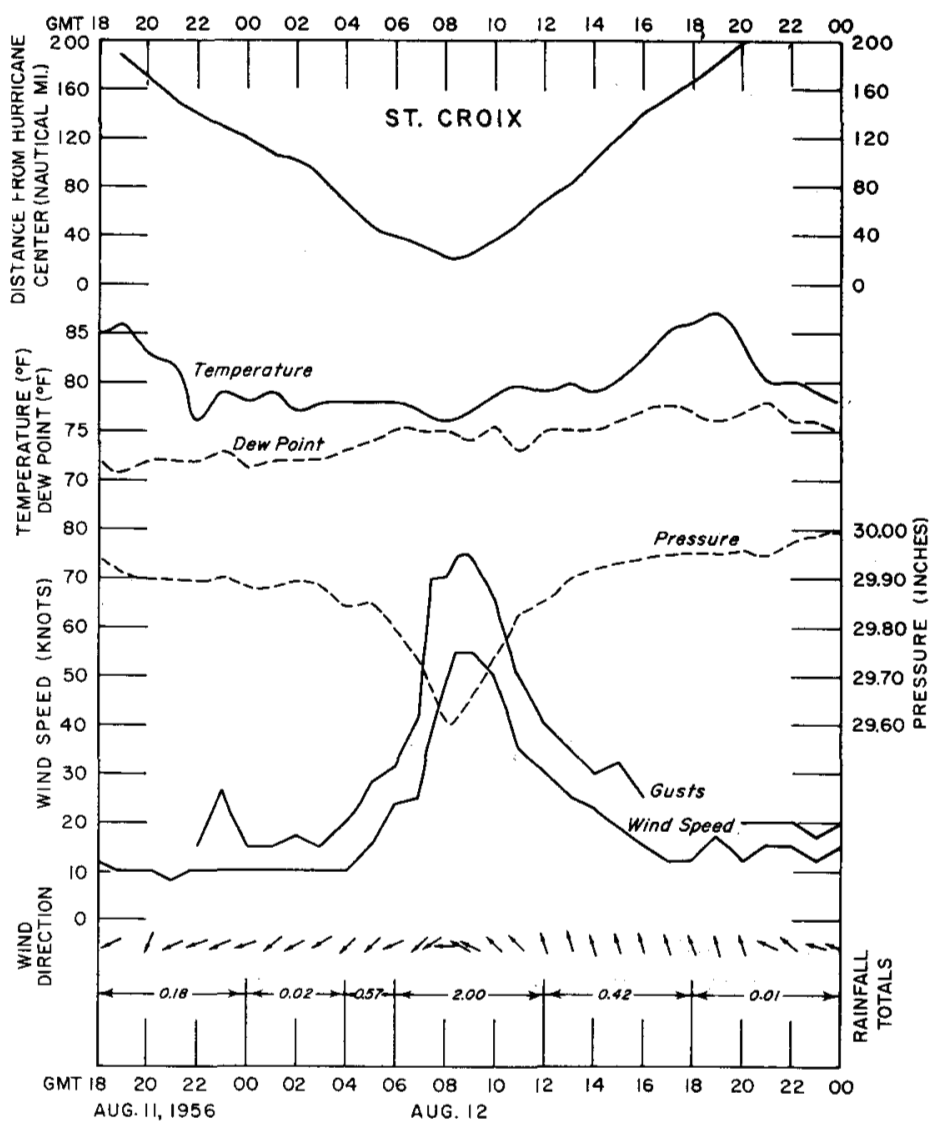

Figure 16.--Meteorological observations at Hamilton Airport, St. Croix, V.I., during the passage of hurricane Betsy, August 11-12, 1956. Time scale in GMT.

During the approach of the hurricane the variations in wind speed, although not the magnitudes, were about the same at the two stations; the wind profile in both cases showed changes in the rate of increase at distances of about 50 and $30 \mathrm{n}$. mi. away from the center. The maximum winds at St. Croix, 55 knots with gusts to 75 , were lower than at San Juan, but the difference was small and probably due to differences in exposure. For the purpose of this discussion, however, this difference in magnitude is not important. The major difference in the observations was in the character of the wind speeds recorded in the rear or departing side of the hurricane. At St. Croix the winds continued strong after the center passed the point of minimum distance. The highest speeds were from the southeast and were evidently associated with the flow in the right rear quadrant. At San Juan, on the other hand, the observations indicate a complete breakdown of the isotach field as soon as the hurricane entered the mountainous area. As a result the wind circulation had decreased considerably by the time the center arrived at the point of minimum distance from the station, and the southeasterly flow in the right rear quadrant of the hurricane was extremely light. Presumably, except for the effect of the mountains, the San Juan area, and similarly every other section on the island, would have been under the effect of stronger winds for a considerably longer period. 


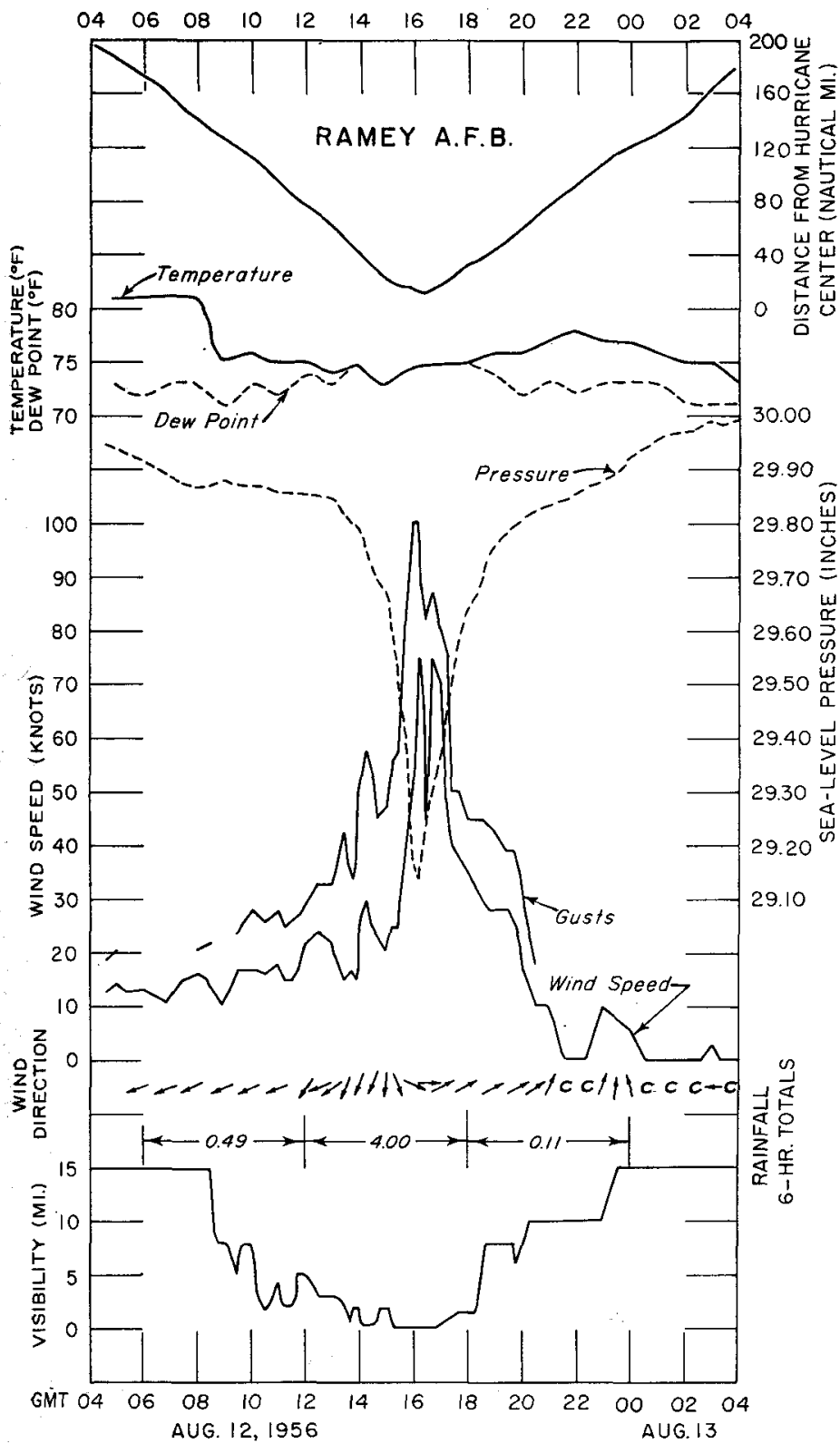

Figure 17.-Meteorological observations at Ramey AFB, P.R., during the passage of hurricane Betsy, August 12, 1956. Time scale in GMT.

The observations at Ramey Air Force Base (fig. 17) make possible certain deductions about the intensification of the hurricane after it moved from land to water on the north side of the island. The winds at Ramey were of the order of 20 knots with gusts of $30-40$ knots up to 1400 aMr when the hurricane, after crossing the mountains, was located about 40 n. mi. east of the station. After 1400 GMT the center moved westward approaching Ramey and at $1500 \mathrm{GMT}$ was located only $22 \mathrm{n}$. mi. away. The winds, however, remained relatively low; the readings around 1500 GMT were about 25 knots with gusts to $50-55$; the maximum reading by that time was 30 knots with gusts to 58. These observations indicate a weaker circulation than would normally be expected in view of the intensity of the hurricane before it entered the island.
After 1500 GMT, when the hurricane center moved over water, there was a sudden and rapid increase in the wind speed; the increase was even more pronounced after 1530 GMT. The maximum intensity, 75 knots with gusts to 100 , was recorded shortly after $1600 \mathrm{GMT}$ at about the time of minimum distance from the center, and also at the time of the minimum pressure. The hurricane was then about $14 \mathrm{n}$. mi. away to the north of the station. There was, evidently, a better organization of the isotach and pressure fields around the eye, and a better coincidence of the pressure and circulation centers than when the hurricane passed close to San Juan. The distribution of rainfall (fig. 19) and damages show also heavier wind and rainfall activity over the northwestern corner than in any other section of the north-coastal area. The pressure observations, discussed in greater detail in the following section, similarly indicate rapid deepening after 1500 GMT. Figure 14 shows the radar picture at the time the hurricane was close to Ramey. The peak wind and rainfall activity there was evidently associated with the southern section of the inner radar band.

\section{PRESSURE OBSERVATIONS}

A series of pressure observations, including some barograph traces, were obtained at a few places on the island. Two sets of observations were taken practically at the center of the hurricane: One at Guayama near the southern coast, and the other at Arecibo, on the northern coast. There was in some cases uncertainty as to the altitude and calibration of the instruments. To remedy this difficulty all observations were corrected to sea level conditions by comparison with the San Juan data. In the cases in which a barogram was available a comparison of the pressure readings during the days previous to or after the passage of the hurricane provided a reliable correction factor. In other cases correspondence with the observers served to clarify the accuracy of the data. All the observations presented in the following discussion were in that form corrected to sea level.

The number of observations available was not sufficient to establish the horizontal field of pressure and to study its changes over land. Instead the central pressure was computed at different positions along the track and the variations with time were studied. The results indicate filling of the central pressure as a result of the motion over the land mass of Puerto Rico followed by rapid deepening as soon as the hurricane moved over water again.

The procedure followed to estimate the central pressure was to determine first a representative value of the pressure gradient in the core of the hurricane and then use it to measure the minimum pressure from observations in the periphery. Various estimations of the gradient were made when the hurricane was centered near the south coast of Puerto Rico and still not greatly affected by the terrain. The barograph trace recorded near the center at Guayama (fig. 18) was very useful in this respect. A 


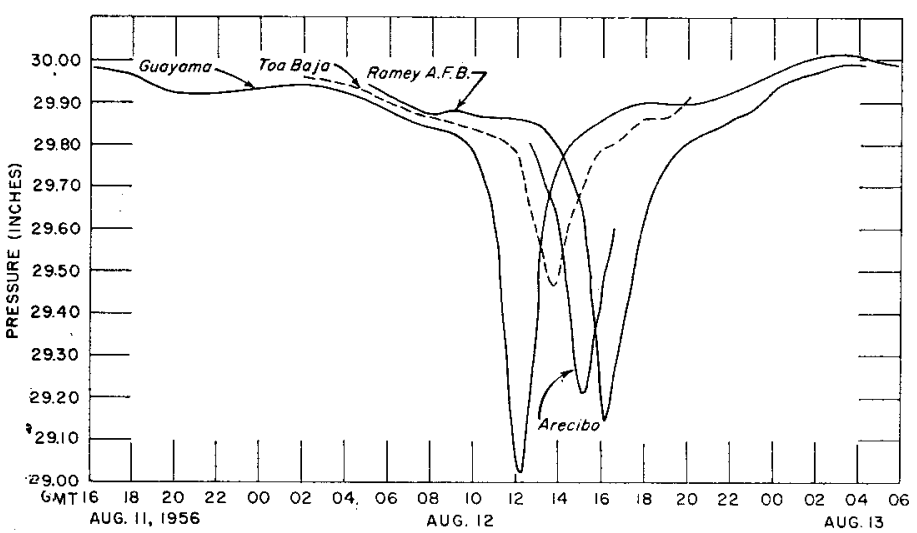

Figure 18.-Pressure profiles during hurricane Betsy, August 12, 1956, as recorded in Guayama, Toa Baja, Arecibo, and Ramey AFB, P.R. Pressures reduced to sea level. See text.

value of $1.0 \mathrm{mb}$. n. mi.-1 was accepted for stations located within $15 \mathrm{n}$. mi. of the center. For the estimations from the readings at St. Croix, San Juan, and Ponce, located 19-22 miles from the center, a gradient value of $0.9 \mathrm{mb}$. n. mi. ${ }^{-1}$ was used; while for Roseau, Dominica, a value of $0.8 \mathrm{mb} . \mathrm{n}$. mi..$^{-1}$ was applied. A tabulation of the pressure readings and estimated central pressures appears in table 1 .

A minimum sea level pressure of $983 \mathrm{mb}$. was recorded at Guayama around $1215 \mathrm{GMT}$ in a position 1 to 2 miles to the left of the radar center, and shortly after the hurricane had entered land. This observation was probably close to, but not exactly at, the center of ninimum pressure, and therefore the central pressure at the time was somewhat lower, perhaps $981 \mathrm{mb}$. or even less. A minimum central pressure of $979 \mathrm{mb}$. was measured by a reconnaissance aircraft when the hurricane was located over the Atlantic on August 10. The minimum pressure observations made during the intermediate period at Roseau, Dominica; Point-au-Pitre, Guadeloupe; and St. Croix, V.I. indicate central pressures that do not differ significantly from the above. Evidently no appreciable filling or deepening of the pressure field occurred from the time the hurricane was first reconnoitered on August 10 until it arrived on the coast of Puerto Rico.

A minimum pressure of $989 \mathrm{mb}$. was read at Arecibo in a position practically at the center, around $1500 \mathrm{GMT}$, at the time that the hurricane was leaving land. Again the minimum central pressure at the time might have been slightly lower. This observation indicates a filling of about 6 to $8 \mathrm{mb}$. from the observation made on the southern coast. Other pressure observations were made at San Juan, Ponce, and Toa Baja (fig. 18) when the hurricane was moving over the mountains; all three of them are quite reliable. The estimations of central pressure from these stations are subject to greater inaccuracies, but in general they corroborate the readings at Guayama and Arecibo.

About 1 hour after the observation at Arecibo, Ramey $A F B$ recorded a minimum pressure of $987 \mathrm{mb}$. in a posi-
TABLE 1.-Tabulation of minimum pressures and estimated central I pressures associated with hurricane Betsy, August 10-13, 1956

\begin{tabular}{|c|c|c|c|c|}
\hline Station & $\begin{array}{c}\text { Date and } \\
\text { time } \\
\text { (GMT) }\end{array}$ & $\underset{\substack{\text { pressure } \\
(\mathrm{mb} .)}}{\text { Minimum }}$ & $\begin{array}{c}\text { Distance } \\
\text { from center } \\
\text { (n. mi.) }\end{array}$ & $\begin{array}{l}\text { Estimated } \\
\text { central pres. } \\
\text { sure (mb.) }\end{array}$ \\
\hline USN Aircraft, $15^{\circ} \mathrm{N} ., 57^{\circ} \mathrm{W}$ & Aug. 10 & 979 & 0 & 978 \\
\hline $\begin{array}{l}\text { Roseau, Dominica } \\
\text { Point-au-Pitre, Guadeloupe, F.W.I. }\end{array}$ & $\begin{aligned} & \text { Aug. } 11 \\
& 1800 \\
& 1800\end{aligned}$ & $\begin{array}{r}1006 \\
991\end{array}$ & $\begin{array}{l}29 \\
12\end{array}$ & $\begin{array}{l}981 \\
979\end{array}$ \\
\hline $\begin{array}{l}\text { St. Croix, V.I } \\
\text { Guayama, P.R.R } \\
\text { San Juan, P.R. } \\
\text { Ponce, P.R R } \\
\text { Toa Baja, P.R } \\
\text { Arecibo, P.R. } \\
\text { Ramey, AFB, P.R }\end{array}$ & $\begin{array}{r}\text { Aug. } 12 \\
0830 \\
1230 \\
1300 \\
1330 \\
1350 \\
1500 \\
1600\end{array}$ & $\begin{array}{r}1002 \\
983 \\
1003 \\
1000 \\
998 \\
989 \\
987\end{array}$ & $\begin{array}{r}22 \\
1-2 \\
22 \\
19 \\
13 \\
0-1 \\
14\end{array}$ & $\begin{array}{l}982 \\
981 \\
983 \\
983 \\
985 \\
989 \\
973\end{array}$ \\
\hline USAF Aircraft, $22^{\circ} \times ., 72^{\circ} \mathrm{W}$ & Aug ${ }_{1400}$ & 972 & 0 & 972 \\
\hline
\end{tabular}

tion $14 \mathrm{n}$. mi. to the south of the radar center. This observation indicates a central pressure of about $973 \mathrm{mb}$.; that is, a deepening of around 15 to $16 \mathrm{mb}$. to a value even lower than had been observed previously. About 22 hours later on August 13 a reconnaissance aircraft measured $972 \mathrm{mb}$, at the center near $22^{\circ} \mathrm{N}$., $72^{\circ} \mathrm{W}$., which tends to substantiate the accuracy of the estimation from Ramey.

Admittedly the method outlined above for estimating the central pressure is rather crude. One serious drawback is the fact that the track of the pressure center does not necessarily coincide with the circulation or the radar track. The Hydrometeorological Section, U.S. Weather Bureau [6] found that the pressure center was most frequently displaced ahead and slightly to the right of the circulation center. The displacement was mostly either ahead or behind and not so much to the right or to the left of the circulation track. This is encouraging because a displacement of the pressure minimum ahead or behind the track, but still close to it, would not seriously invalidate the above computations. Nevertheless, although quantitative estimates of the central pressure and its variations have been presented the main conclusions can be well sustained by qualitative reasonings.

It is quite evident that if the pressure minimum was displaced significantly to the right or to the left of the radar track the conclusion regarding the filling of the central pressure over land would still be valid on the basis of the observations at Guayama and Arecibo. Furthermore, if it is assumed that the pressure minimum was displaced to the right of the radar track, then the estimate of the central pressure at Toa Baja should be higher than indicated in table 1, thus corroborating the amount of filling over land. At the same time a displacement of the pressure minimum to the right of the track would not alter the magnitude of the deepening between the observations at Arecibo and Ramey. The only possibility that might affect the results is that the pressure minimum was displaced to the left of the track between 1500 and 1600 GMT. In that case the conclusion concerning the amount of deepening between Arecibo and Ramey would be altered. Such a possibility, however, is not very likely; and it is not supported by the observations in the rest of the island. A detailed scrutiny of the available data suggests that at the time the hurricane was moving over the moun- 


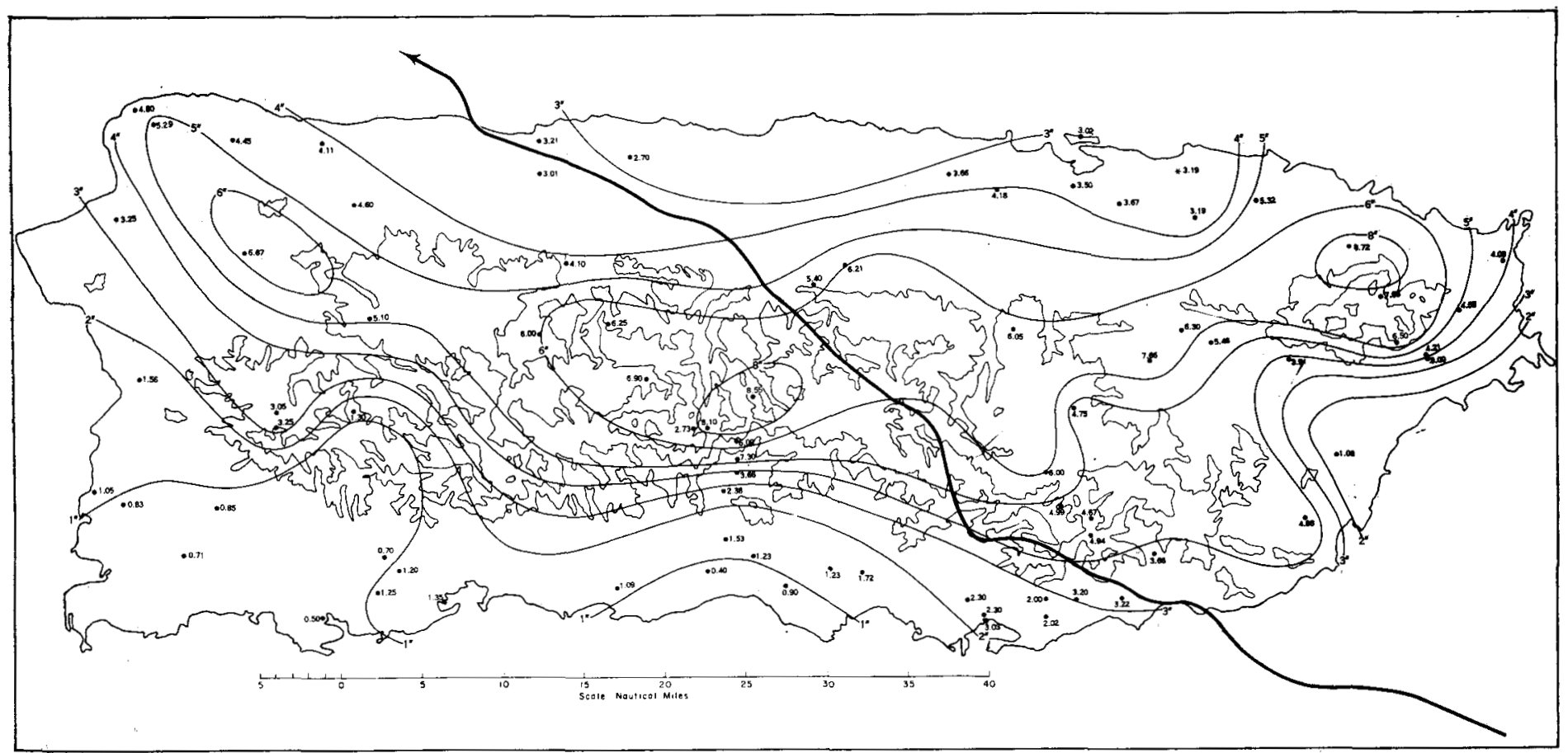

Figure 19.-Distribution of total rainfall recorded over Puer to Rico during the passage of hurricane Betsy. Track of the center is heavy line.

tains between 1200 and 1400 GMT the pressure minimum was probably displaced ahead and somewhat to the right of the radar track.

There are, of course, other sources of error in the pressure evaluations, aside from the relationship between the pressure and radar tracks. All factors considered, the pressure estimates listed in table 1 are quite reasonable and not unexpected. They exactly verify what one would normally anticipate in such a situation. One thing that is striking is the rapidity and magnitude of the deepening that took place when the hurricane moved again over water on the north side of the island. This result attests to the tremendous influence of water surface on the organization and maintenance of the hurricane circulation.

\section{RAINFALL OBSERVATIONS}

Figure 19 shows the distribution of rainfall over Puerto Rico during hurricane Betsy. The amounts range from values of about half an inch in the southern coastal areas to over 8 inches in the northeastern and central mountainous sections. The rainfall was greater on the right side of the track south of the mountain range and on the left side of the track north of the range. Evidently this distribution was mostly the result of orographic effects. The southern coastal areas to the left of the track were shielded by the mountains and thus the rainfall and wind effects were reduced. On the other hand the sections exposed to the action of the wind were affected more. The zone of heavier rainfall extending southeast-northwest over the northwestern section of the island was probably associated with the regeneration of the hurricane circulation after the center moved over water. There was prob- ably another band of heavy rainfall over the oceanic area on the right side of the track.

A comparative study was made of the rainfall totals associated with hurricane Betsy and those of the great San Felipe hurricane of September 13, 1928 [2]. The path of the San Felipe hurricane acioss Puerto Rico was fairly close to that of Betsy; it entered land in about the same location as Betsy, passed about $25 \mathrm{n}$. mi. to the southwest of San Juan, and left the island through the northwestern corner. On that occasion San Juan recorded a minimum pressure of $973 \mathrm{mb}$. and a maximum wind of 160 m.p.h., which still rates as one of the highest hurricane winds ever measured. There were 11 consecutive hours of winds greater than 60 m.p.h. and about 6 hours of winds over 100 m.p.h. During hurricane Betsy San Juan recorded only 1 hour of winds greater than 60 m.p.h. On the basis of the observations at San Juan the radius of the intense inner core of the San Felipe hurricane was estimated as about $180 \mathrm{n}$. mi., as compared to only $50 \mathrm{n}$. mi. for hurricane Betsy. Hurricane Betsy was, therefore, relatively small.

The rainy period at San Juan during hurricane Betsy lasted 13 hours and 3.19 inches of rain were measured. During hurricane San Felipe 9.37 inches were measured in a period of 33 hours. Dividing the total rainfall by the length of the period gives a value representing average rainfall per hurricane-hour. This came out as 0.28 inch per hour for hurricane San Felipe and 0.25 for hurricane Betsy. Similar computations were tried for 36 stations over the island that had rainfall records in both hurricanes. It was assumed that the length of the rainy period at each station during San Felipe was greater 
than during Betsy in the same relation, 33 to 13, that was observed at San Juan. In view of the similarity in the tracks this assumption is reasonable. The results were remarkably equal, station for station; the average for all 36 stations was 0.28 inch per hurricane-hour in San Felipe and 0.26 in Betsy. In other words the average rainfall per hour was about the same in the two hurricanes in spite of the tremendous difference in their size and intensity. Apparently the intensity of the hurricane is not as important in determining the total rainfall at a station as the size and speed of motion, which in turn determines the length of the period it affects the station. This result, if it proves to be true in general, might be useful in predicting total rainfall and ensuing flood conditions in a similar situation.

\section{ACKNOWLEDGMENTS}

The writer wishes to express his appreciation to several people, who, directly or indirectly, contributed to the completion of this report. Mr. Ralph L. Higgs assisted in securing some of the original data, and gave valuable encouragement and advice. Messrs. David Smedley and Americo Maldonado also contributed in assembling data. Messrs. Harry M. Hoose and D. C. McDowell read the manuscript and gave valuable suggestions. The interest and spirit of cooperation of amateur weather observers over the island who recorded observations and made them available to the Weather Bureau is deeply appreciated.
In particular the contributions of Mr. J. M. de Andino, from Guayama, P.R., Mr. Luis G. Veray, from Central Constancia in Toa Baja, P.R., and Mr. Andres Gelabert, from Arecibo, P.R. proved to be extremely useful. The authorities at Ramey AFB, and U.S. Naval Base, San Juan, kindly made their meteorological observations available for this study; their valuable cooperation is sincerely acknowledged.

\section{REFERENCES}

1. Gordon E. Dunn, Walter R. Davis, and Paul L. Moore, "Hurricane Season of 1956," Monthly Weather Review, vol. 84, No. 12, Dec. 1956, pp. 436-443.

2. O. L. Fassig, "San Felipe-The Hurricane of September 13, 1928 at San Juan, P.R.," Monthly Weather Review, vol. 56, No. 9, Sept., 1928, pp. 350-352.

3. John D. Horn, "On Irregular Movements of Tropical Cyclones in the Pacific," Bulletin of the American Meteorological Society, vol. 32, No. 9, Nov. 1951, pp. 344-346.

4. William Malkin and George C. Holzworth, "Hurricane Edna, 1954," Honthly Weather Review, vol. 82, No. 9, Sept. 1954, pp. $267-279$.

5. Vaughn D. Rockney, "Hurricane Detection by Radar and Other Means," Proceedings Tropical Cyclone Symposium, Brisbane. Austrialia, Dec. 10-14, 1956, Melbourne, 1956, pp. 179-197.

6. U.S. Weather Bureau, "Characteristics of United States Hurricanes Pertinent to Levee Design for Lake Okeechobee, Florida," Hydrometeorological Report No. 32, March 1954, 106 pp.

7. T. -C. Yeh, "The Motion of Tropical Storms under the Influence of a Superimposed Southerly Current," Journal of Meteorology, vol. 7, No. 2, April 1950, pp. 108-113. 